\title{
The Use of Pluripotent Stem Cell for Personalized Cell Therapies against Neurological Disorders
}

\author{
Hye-Yeong Ha, Si-Hyong Jang, and Ji-Won Jung \\ Division of Intractable Diseases, Center for Biomedical Science, Korea National Institute of Health, Cheongwon-gun, \\ Chungbuk 363-700, Republic of Korea \\ Correspondence should be addressed to Ji-Won Jung, infranova@gmail.com
}

Received 17 July 2011; Accepted 4 November 2011

Academic Editor: Ken-ichi Isobe

Copyright ( $\odot 2011$ Hye-Yeong Ha et al. This is an open access article distributed under the Creative Commons Attribution License, which permits unrestricted use, distribution, and reproduction in any medium, provided the original work is properly cited.

\begin{abstract}
Although there are a number of weaknesses for clinical use, pluripotent stem cells are valuable sources for patient-specific cell therapies against various diseases. Backed-up by a huge number of basic researches, neuronal differentiation mechanism is well established and pluripotent stem cell therapies against neurological disorders are getting closer to clinical application. However, there are increasing needs for standardization of the sourcing pluripotent stem cells by establishing stem cell registries and banking. Global harmonization will accelerate practical use of personalized therapies using pluripotent stem cells.
\end{abstract}

\section{Introduction}

Infectious diseases have been life-threatening with the aid of newly emerging ones caused by environmental and sociocultural changes of human life. However, coping with infectious agents is being accelerated and accurate by scientific achievement resulting in antibiotics and vaccines development, so that importance of managing physical damages caused by external wound or physiological disorders of internal origin is being important in the present.

Approaches to cure the wound-mediated loss of physical function or genetic disorders had been focused on prevention from worsening of damage to deteriorate neighboring tissue or organs using medicinal and surgical efforts. Along the 20th century's era of organ transplantation, recent approaches of regenerative medicine using stem cell are emerging as a sensation in biomedical sciences in 21st century and provoking an innovative development in medicine.

It is expected that personalized regenerative medicinal approach using stem cells will be accelerated by continuous huge investment and research efforts throughout the world. Since human embryonic stem cell (hES) was first established in 1998 [1], researches to establish pluripotent stem cells, that is, ES cells, or isolate stem cells from various adult tissue or organs and to differentiate them into target tissues of therapeutic interest such as neuronal, cardiovascular, pancreatic, and hepatic lineages have been progressed and the possible outcomes are expected to be utilized as personalized therapeutics and as basic research tools for disease modeling. Although there are still challenges for practical application of stem cell therapies in clinical use in the present, however, the growing number of clinical trials for therapies using adult stem cells of various human tissue origin as well as hES cells is increasing public expectation for practical use of stem cell therapies in regenerative medicine (http://www.clinicaltrial.gov/). Here we reviewed what is current status of personalized therapies for neurological disorders using pluripotent stem cells and what is needed to further expand their application in practical use.

\section{Pluripotent Stem Cells as Sources for Personalized Stem Cell Therapy}

Pluripotent stem cells have infinite proliferative potential and capacity to differentiate into three germ layer-derived cell types of a body: ectoderm, endoderm, and mesoderm. Pluripotent stem cells comprise ES cells and, more recently, induced pluripotent stem (iPS) cells.

ES cells are derived from the inner cell mass of blastocyst [1]. ES cells can generate all type cells of three germ layer 
origin while adult stem cells are thought to be limited in differentiation potential into various cell types of tissue origins. In comparison to adult stem cells which have limitation in ex-vivo proliferation, ES cells can be grown indefinitely in cell culture of optimized condition. With those natures, ES cells are beneficial as a source of cell replacement therapies for supplying a large number of cells needed for therapeutic application stably.

The iPS cells are reprogrammed from somatic cells by introduction of a number of ES cell-specific genes, mainly OCT4, SOX2, KLF-4, C-MYC, LIN28, and NANOG. The introduction of iPS cell by Shinya Yamanaka brought huge scientific interest into stem cell and regenerative medicine field because of biomedical and socioeconomical impacts of iPS cells [2-5]. Until now the technical improvement related to iPS cells generation is ongoing by using diverse cell types, different factors, and various methods [4-6].

Major advantages of iPS cells can be described by two aspects. First, the method of iPS cell establishment is free of ethical concern by which hES cells are critically screened before utilizing in research. Second, iPS cells are patientspecific source of pluripotent stem cell because the cells are originated from patients' somatic cells by introducing a number of ES-specific genes [2, 3, 7]. So to speak, patientspecific iPS cells are unlimited source of autologous stem cell therapy with perfect match of leukocyte antigen, and then we may overcome a hurdle of graft versus host interaction. Moreover, somatic cells from patients with genetic disorders have been reprogrammed to make iPS cells and then differentiated into disease-specific tissues for modeling, investigating disease pathophysiology and then drug discovering [8-10].

However, there are a number of reports for limitations of current technologies that hinders iPS cells into practical use. First, increase of tumor formation possibility is reported $[11,12]$. Introduction of c-MYC protooncogene as one of reprogramming factors increases tumor formation. In addition, retro or lentiviral transduction of reprogramming factors causes not only epigenetic reconfiguration but also genetic modification which may lead to cancer formation $[13,14]$. Second, it was reported that mouse iPS cells have immunogenicity to syngeneic recipient. This suggests that, although iPS cells are conceived to be immune-tolerated to autologous recipients, there are still hurdles to overcome to establish more ES-like iPS cells in terms of completeness [15].

Supported by the numerous research milestones for the achievement in pluripotent stem cells both hES and iPS cells, their clinical usage is being realized. A couple of clinical trials are undergoing (http://www.clinicaltrial.gov/); however, practical application of pluripotent stem cells is mainly being evaluated at the level of research and development. In order to solve remained controversy and problems many basic issues left to be done: to understand how to control stem cell proliferation and differentiation into specific cell types, to enhance survival in recipient, to prevent immune rejection and induce their integration into recipient cellular network, and to optimize the functional recovery of damaged tissue or organs in human disease. In addition, the use of pluripotent stem cells should solve the problems of the immune rejection of grafted stem cells and tumor formations in cell replacement therapy.

\section{Historical Aspect of Personalized Therapies Using Stem Cells in Neurological Disorders}

As above mentioned, stem cells have promised to revolutionize the future of regenerative medicine through the cell replacement therapies to treat a variety of deliberating diseases. Although using pluripotent stem cell for treatment is relatively new, convincing evidence has emerged the capability of various stem cell populations used for treatment of various diseases. The applications of stem cell therapies for treating neurological disorders are enormous. Mimicking the neural stem cell activity, the treatment of neurological disorders is based on the ideas that the replacement of damaged cells and the restoration of brain homeostasis can be achieved through transplantation of stem cell. Many laboratories have attempted stem cell treatment for central nervous system diseases, including spinal cord injury, stroke, amyotrophic lateral sclerosis, Parkinson's diseases, multiple sclerosis, and epilepsy [16-22].

The first nonhematopoietic bone marrow-derived multipotent stromal cells (BMSC) were reported in 1976 [23]. From the beginning, BMSCs were focused for cell therapy because they are easily obtained from human bone marrow aspirates, rapidly expanded in culture. Moreover, it was reported that BMSCs can be used autologously and do not form tumors after transplantation [24]. In recent report, the clinical trial for strokes with intravenous BMSC treatment long-term follow-up showed that the improved survival statics compare with control [25].

Fetal Neural Stem Cells (NSCs) can be derived from human fetal brain and capable of differentiating into neurons, astrocytes, and oligodendrocyte [26]. The fetal NSCs are generally isolated from abortus and their use is conceived less ethically controversial than hES cells. There is available evidence that supports efficiency of intrastriatal transplantation of human embryonic mesencephalic tissues in Parkinson's disease. These studies demonstrated that grafted dopamine neurons can survive, reinnervate the striatum, and restore dopamine release for up to 10 years despite an ongoing disease progress, which destroys Parkinson's disease patient's own dopamine neurons [27, 28]. However, a number of recent postmortem studies examined longterm fetal transplants in Parkinson's diseases have revealed that host pathogenic factors affect the transplants and their recipients [29-31]. The long-term clinical follow-up in six individuals who survived 9-16 years after the fetal neuronal tissue transplantation showed that the effect of transplantation is limited and three of them showed typical brain pathology of Parkinson's diseases at autopsy [29-31]. These indicate that the engrafted cells may be affected by the disease process of the recipients weakening the long-term clinical benefits as a therapeutic approach.

Over the last decade, there has been a rapid advance in research of pluripotent stem cells including ES and iPS cells. Many studies suggested that ES cells have the ability to generate variety of types of cells in neuronal lineages 
including neural progenitor, neurons, oligodendrocyte, and astrocyte [32-37]. In addition, accumulating data have proven the therapeutic efficacy of hES cell-derived neural precursor cells (NPCs) in experimental model of neurological diseases $[33,34,38,39]$. Recently a number of reports showed the use of iPS cells to treat several neurological disorders such as Parkinson's and Huntington's disease, spinal muscular atrophy, amyotrophic lateral sclerosis, and spinal cord injuries $[4,21,40,41]$.

The generation of iPS cells from a somatic cell having genetic disease patients offers the opportunity to disease modeling and possibility for treatment in personalized cell therapy by accelerating drug discovery. Patient-specific iPS cells from degenerative neurological diseases such as familial dysautonomia [8] and adrenomyeloneuropathy [42] opened possibility to comprehend disease mechanism and discover drug to moderate symptoms.

\section{In Vitro Differentiation into Neural Lineage from ES Cells}

Establishment of efficient and stable in vitro method for neural differentiation is an important preceding process for clinical application of pluripotent stem cells [43]. Characteristically, nervous system is composed of heterogeneous populations mixed with a variable cell types including neurons, astrocytes, oligodendrocytes, and their precursor cells [44]. To make these variable neural components during normal development, a part of ES cells undergoes neural induction and rostrocaudal and dorso-ventral patterning. Throughout these steps, human nervous system is assorted by forebrain, mid and hind brain, and spinal cord. After then temporal and spatial patterning is followed, resulting in differentiation of cortical progenitor cells into generate subtypes of neurons and formation of cortical structures with six layers. Each subtype of neurons has its own specific function and its damages and defects are associated with different types of diseases or disabilities, undoubtedly [45]. Many previous researchers have tried for efficient derivation of many mature cell lines from pluripotent stem cells. Unfortunately, in vitro differentiation process cannot be always reflected to in vivo differentiation steps in neurogenesis. Additionally transcriptional variability between the hES cell lines and also their differentiated neural cells is remained, reflecting the heterogeneity in the way the ES cells were established [46]. Here, we introduce and summarize the representative protocols and mechanisms of the neural differentiation from the pluripotent stem cells.

In vitro neural differentiation of pluripotent stem cells involves three main stages of neural induction, expansion of neural progenitor cells, and differentiation to neurons and glial cells $[47,48]$.

In earliest procedures for neural induction, hES cells were led to spontaneous differentiation into embryoid body and then neural progenitor cells appearing rosette-like structures were mechanically isolated [36]. With identification of various differentiation-related cellular mechanisms and pathways, the inhibition of bone morphogenetic proteins (BMPs) and/or SMAD signaling pathways is known to be necessary for efficient induction of neural induction of hES cells. BMPs are members of transforming growth factor-beta (TGF $\beta$ ) and activate the specific type I and type II receptors, leading to phosphorylation of their downstream SMAD [47]. Using this mechanism, Chambers et al. [49] have designed an efficient protocol for neural conversion from one ES and two iPS lines. They treated with recombinant Noggin and drug SB431542 for combined dual inhibition of SMAD signaling and identified expression of neuroectodermal markers, PAX6 and SOX2, in mRNA and protein levels [49]. Another study demonstrated that hES cells can differentiate into the Pax6+/Sox $1+$ neural rosette in the presence of noggin and supplemental addition of fibroblast growth factor (FGF) [50]. Additionally, inhibition of FGF signaling pathway led to impairment of neural induction, suggesting that FGF signaling can implicate in the neural specification stages independently of BMP signaling [51]. More recently, it is found that coincident blockade of Activin/Nodal and BMP pathways by SB431542 and dorsomorphin enhances the neural differentiation in variable pluripotent stem cell lines. An advantage of this protocol is that the differentiation efficacy is constant neural regardless of the divergence [48].

Following neural induction, neural expansion process should be announced. In this stage, the neural precursor cells in EBs are expanded in suspension culture with media usually containing mitogenic factors, such as bFGF or epidermal growth factor (EGF) [47, 48]. WNT signaling pathway is thought to be contributed for formation and maintenance of hES cell-derived neurosphere in this stage [52].

In the next stage, hES cell-induced and -expanded neural progenitor cells are differentiated into neural or glial cells. Plating of the precursor cells on the laminin, fibronectin or matrigel substrates promotes differentiation of the precursor cells to neurons and glia. In addition, absence of previously treated mitogenic factors helps their differentiation process into mature cell lines $[47,48]$. A study found that the determination of the cell lineages is governed by combined activation of some signaling pathway including Rho/ROCK and PI3K/Akt pathways [47].

The final stage of the in vitro neural differentiation process is a neural specification that means terminal differentiation of immature cells into full matured cells with acquisition of their own typical cellular functions. Combined treatment of various cytokines in mid-stage neural cells makes various types of mature function-specific neural cells. It is very important to reveal how to differentiate to a specific neural cell lineage for replacement therapy using ES cells as a substitution of abnormal or malfunctioning cells. Selective loss of dopaminergic neurons in the substantia nigra is a characteristic of Parkinson's disease and many studies have developed the methods for differentiating from ES cells to mature dopaminergic neurons [36]. Both Shh and FGF8 are considered as important ligands for production of dopaminergic neurons. Biologic effects of these molecules in neurogenesis support the evidence of addition of Shh and FGF8 in the culture media that have been applied in most previous described protocols $[36,53,54]$. For differentiation into glial lineages, treatment of FGF2 followed by treatment 
of PDGF, IGF, NT3, and Shh generates oligodendrocytic differentiation of hES cells [55]. Another glial cell types, mature astrocytes, can be produced from hES cells by using cyclopamine, Shh inhibitors, and human astrocytes mudium [56].

\section{Epigenetic Regulations in Embryonic Development as well as Neural Differentiation}

Epigenetic changes mean heritable alterations of gene expression in the absence of changes in DNA sequence. Epigenetic events include DNA methylation, histone modification, and nucleosome remodeling, leading to structural changes of chromatin and subsequent transcription regulation [57]. Polycomb group proteins $(\mathrm{PcG})$ are representative regulators of epigenetic changes and they are conservative components from Drosophila to humans. Structurally they form distinct multimeric complexes, called Polycomb repressive complexes (PRCs), classified as two groups, PRC1 and PRC2. PRC2 is composed of EZH2, SUZ12, and EED, which acts as initiators of transcription inhibition [58]. PRC1 can recognize the trimethylates lysine 27 occurred by PRC2 through the chromodomain and maintain the gene repression status [59].

The expression of ES cell and their development-related genes are modified by epigenetic regulatory factors [60]. PcG is known to be an essential constituent for maintaining the properties of ES cells by regulation of the transcription factors OCT4, SOX2 and NANOG, all that are expressed in undifferentiated status and are associated with ES cell selfrenewal and pluripotency [58]. As differentiation progressed, pluripotent genes including OCT4, SOX2, and NANOG are downregulated by methylation on the promoter region [61]. On the other hand, differentiation-related genes expressing in hematopoietic stem cells and neural progenitor cells are activated by demethylation of their promoter region [58]. PRCs also play crucial roles as inhibitors of differentiation. Using genetic ontology, a study demonstrated that the functions of PcG-binding genes in hES cells are involved in development, transcription regulation, organogenesis and neurogenesis. Hox, GATA, NeuroD, FOX, POU, and MYO are controlled by PcG and it means that PcG represses the expression of differentiation-promoting genes. This study demonstrated that SUZ12 occupies a subset of differentiation-promoting genes also bound by OCT4, SOX2, and NANOG in hES cells [58]. Another study revealed that when ES cells experienced spontaneous differentiation forming embryoid body (EB), PcG-binding genes are specifically activated in differentiated state or EBs [61]. PcG can closely and delicately regulate the expression of both pluripotent and differentiated genes to proper development.

In in vivo studies, PcG also is proven to be concerned in organogenesis and differentiation of pluripotent stem cells. PRC2 subunits (Eed, Ezh2, Suz12) knockout mice suffered a congenital defect in gastrulation [62-64]. EED or Suz12 knockout murine ES cells showed decreased H3K27 methylation as well as abnormally increased expression of differentiation-related genes, suggesting the epigenetic changes produced by Eed, Suz12 and histone methylation contribute the differentiation process $[63,65,66]$. Another study revealed that Suz12 knockout murine ES cells fail to achieve the primary neuroepithelial development [66]. Thus, epigenetic regulation is necessary for appropriate development and differentiation on pluripotent stem cells.

Neural differentiation from ES cells is also effected by epigenetic events, such as methylation or acetylation. Among the epigenetic events, $\mathrm{H} 3 \mathrm{~K} 4$ trimethylation and $\mathrm{H} 3 \mathrm{~K} 9$ methylation were found to play roles in repressing the pluripotency- and differentiation-associated genes during neurogenesis from hES cells, respectively [67]. Moreover, Bmi-1, one of the polycomb group proteins, allows maintaining the self-renewal and proliferation of neural stem cells. Bmi-1 knockout neural stem cells have a decreased clonogenic capacity and proliferative index, in which epigenetic change is implicated in maintaining stemness [68-71]. Another PcG, Ring 1B, is also concerned with maintenance of pluripotency and self-renewal in ES stem cell-derived neural precursor cells. Ring 1B deficient ES cell-derived neural stem cells show a decreased efficacy and size of neurosphere formation as well as increased neural induction [68-71]. EZH2 expression can determine the lineage of cell differentiation in the murine neural stem cells. Overexpression of EZH2 promotes the oligodendrocytic differentiation and concordantly impedes the astrocytic differentiation [72]. Therefore, epigenetics cannot only be an important factor to maintain pluripotency but also determine the cell fate. If we use this epigenetic effect on differentiation of ES cells, we will be able to establish more efficient and stable cell lines for treatment. In fact, recently reported studies found that histone deacetylase inhibitor, sodium butylate, has an effect for improvement of the neural differentiation induction from murine ES cells $[73,74]$.

\section{Recent Advance of Personalized Therapies Using Pluripotent Stem Cells}

Use of pluripotent stem cells in personalized therapies has made rapid progress to practical application accumulating growing evidence in different pathophysiological conditions in small and larger animal models. Clinical trials are a major step in the development of personalized stem cell therapies into practical application. As of 30, June, 2011, there are 3604 ongoing clinical trials of stem cells worldwide (http://www.clinicaltrial.gov/). Although the number of clinical trials using human pluripotent stem cells is only limited to two, however, recent approval of the human pluripotent stem cell clinical trials provides new prospects for cell replacement strategies in a broad spectrum of human neurological disorders. The Geron Corporation has initiated the first clinical trials of an ES cell-based therapy on human. This study will evaluate the drug GRNOPC1, ES cell-derived oligodendrocyte progenitors, on patients with acute spinal cord injury. Consequently, Advanced Cell Technology has secured FDA clearance to proceed with two separate Phase $1 / 2$ clinical trials to test the safety of the hES cell-derived 
retinal pigment epithelial (RPE) cellular therapy for Dry AgeRelated Macular Degeneration and for Stargardt's Macular Dystrophy.

Although it is sure that the clinical trials of hES cellderived therapy will strengthen possibility of personalized therapies using pluripotent stem cells in practical application, however, immunological diversity of human leukocyte antigens (HLAs) is a problem remained. As already mentioned, patient-specific iPS cells have many hurdles to get over for practical application to human body such as tumor formation and possible immune rejection mediated by aberration of genetic integrity. Expanding an allogeneic pool of in high-standard "clinical grade" hES cell lines established at utmost ethical mandate might be a way to accelerate clinical application of personalized pluripotent stem cell therapies by increasing chances to find HLA-matched cell source [7577]. As an effort, there are increasing needs for pluripotent stem cell registry and banking worldwide and the number of them is being increased [78-81]. There are a number of well-organized pluripotent stem cell registries running based on government worldwide such as NIH Human Embryonic Stem Cell Registry (http://escr.nih.gov), European Embryonic Stem Cell Registry (http://www.hescreg.eu/), and Korea Stem Cell Registry (http://kscr.nih.go.kr/). The International Stem Cell Banking Initiative (ISCBI) is a global network of stem cell banks that aims to facilitate practical application of stem cell research by harmonizing stem cell banking on a global level $[78,79]$. It is expected that the pluripotent stem cell-based personalized therapies will be strengthened by international collaboration, harmonization, and standardization for establishment, characterization, and qualification of the pluripotent stem cell as well as differentiation into functional tissues. Moreover, convergence of cutting-edge sciences such as systems biology and informatics approaches into pluripotent stem cell registries and banking will be needed for further enhancement of personalized therapeutic application of pluripotent stem cells.

\section{Author's Contribution}

Hye-Yeong Ha and Si-Hyong Jang are equally contributed.

\section{Acknowledgment}

The authors are supported by an intramural research grant from the Korea National Institute of Health (4845-300-21013).

\section{References}

[1] J. A. Thomson, J. Itskovitz-Eldor, S. S. Shapiro et al., "Embryonic stem cell lines derived from human blastocysts," Science, vol. 282, no. 5391, pp. 1145-1147, 1998.

[2] K. Takahashi, K. Tanabe, M. Ohnuki et al., "Induction of pluripotent stem cells from adult human fibroblasts by defined factors," Cell, vol. 131, no. 5, pp. 861-872, 2007.

[3] K. Takahashi and S. Yamanaka, "Induction of pluripotent stem cells from mouse embryonic and adult fibroblast cultures by defined factors," Cell, vol. 126, no. 4, pp. 663-676, 2006.
[4] E. Kiskinis and K. Eggan, "Progress toward the clinical application of patient-specific pluripotent stem cells," Journal of Clinical Investigation, vol. 120, no. 1, pp. 51-59, 2010.

[5] S. M. Wu and K. Hochedlinger, "Harnessing the potential of induced pluripotent stem cells for regenerative medicine," Nature Cell Biology, vol. 13, no. 5, pp. 497-505, 2011.

[6] N. Takayama, S. Nishimura, S. Nakamura et al., "Transient activation of c-MYC expression is critical for efficient platelet generation from human induced pluripotent stem cells," Journal of Experimental Medicine, vol. 207, no. 13, pp. 28172830, 2010.

[7] J. Yu, M. A. Vodyanik, K. Smuga-Otto et al., "Induced pluripotent stem cell lines derived from human somatic cells," Science, vol. 318, no. 5858, pp. 1917-1920, 2007.

[8] G. Lee, E. P. Papapetrou, H. Kim et al., "Modelling pathogenesis and treatment of familial dysautonomia using patientspecific iPSCs," Nature, vol. 461, no. 7262, pp. 402-406, 2009.

[9] G. H. Liu, B. Z. Barkho, S. Ruiz et al., "Recapitulation of premature ageing with iPSCs from Hutchinson-Gilford progeria syndrome," Nature, vol. 472, no. 7342, pp. 221-225, 2011.

[10] M. Yazawa, B. Hsueh, X. Jia et al., "Using induced pluripotent stem cells to investigate cardiac phenotypes in Timothy syndrome," Nature, vol. 471, no. 7337, pp. 230-234, 2011.

[11] M. Stadtfeld and K. Hochedlinger, "Induced pluripotency: history, mechanisms, and applications," Genes and Development, vol. 24, no. 20, pp. 2239-2263, 2010.

[12] K. Takahashi, K. Okita, M. Nakagawa, and S. Yamanaka, "Induction of pluripotent stem cells from fibroblast cultures," Nature Protocols, vol. 2, no. 12, pp. 3081-3089, 2007.

[13] A. Gore, Z. Li, H. L. Fung et al., "Somatic coding mutations in human induced pluripotent stem cells," Nature, vol. 471, no. 7336, pp. 63-67, 2011.

[14] S. M. Hussein, K. Nagy, and A. Nagy, "Human induced pluripotent stem cells: the past, present, and future," Clinical Pharmacology and Therapeutics, vol. 89, no. 5, pp. 741-745, 2011.

[15] T. Zhao, Z. N. Zhang, Z. Rong, and Y. Xu, "Immunogenicity of induced pluripotent stem cells," Nature, vol. 474, no. 7350, pp. 212-215, 2011.

[16] G. B. Boncoraglio, A. Bersano, L. Candelise, B. A. Reynolds, and E. A. Parati, "Stem cell transplantation for ischemic stroke," Cochrane Database of Systematic Reviews, vol. 9, Article ID CD007231, 2010.

[17] G. Martino, R. J. M. Franklin, A. B. van Evercooren, and D. A. Kerr, "Stem cell transplantation in multiple sclerosis: current status and future prospects," Nature Reviews Neurology, vol. 6, no. 5, pp. 247-255, 2010.

[18] A. R. Muotri, "Modeling epilepsy with pluripotent human cells," Epilepsy and Behavior, vol. 14, supplement 1, no. 1, pp. 81-85, 2009.

[19] J. R. Naegele, X. Maisano, J. Yang, S. Royston, and E. Ribeiro, "Recent advancements in stem cell and gene therapies for neurological disorders and intractable epilepsy," Neuropharmacology, vol. 58, no. 6, pp. 855-864, 2010.

[20] V. Sahni and J. A. Kessler, "Stem cell therapies for spinal cord injury," Nature Reviews Neurology, vol. 6, no. 7, pp. 363-372, 2010.

[21] R. P. F. Salewski, E. Eftekharpour, and M. G. Fehlings, "Are induced pluripotent stem cells the future of cell-based regenerative therapies for spinal cord injury?" Journal of Cellular Physiology, vol. 222, no. 3, pp. 515-521, 2010.

[22] A. Uccelli and G. Mancardi, "Stem cell transplantation in multiple sclerosis," Current Opinion in Neurology, vol. 23, no. 3, pp. 218-225, 2010. 
[23] A. J. Friedenstein, U. F. Gorskaja, and N. N. Kulagina, "Fibroblast precursors in normal and irradiated mouse hematopoietic organs," Experimental Hematology, vol. 4, no. 5, pp. 267-274, 1976.

[24] D. G. Phinney and D. J. Prockop, "Concise review: mesenchymal stem/multipotent stromal cells: the state of transdifferentiation and modes of tissue repair-current views," Stem Cells, vol. 25, no. 11, pp. 2896-2902, 2007.

[25] J. S. Lee, J. M. Hong, G. J. Moon et al., "A long-term followup study of intravenous autologous mesenchymal stem cell transplantation in patients with ischemic stroke," Stem Cells, vol. 28, no. 6, pp. 1099-1106, 2010.

[26] O. Lindvall and Z. Kokaia, "Stem cells for the treatment of neurological disorders," Nature, vol. 441, no. 7097, pp. 10941096, 2006.

[27] J. H. Kordower, T. B. Freeman, B. J. Snow et al., "Neuropathological evidence of graft survival and striatal reinnervation after the transplantation of fetal mesencephalic tissue in a patient with Parkinson's disease," New England Journal of Medicine, vol. 332, no. 17, pp. 1118-1124, 1995.

[28] P. Piccini, D. J. Brooks, A. Björklund et al., "Dopamine release from nigral transplants visualized in vivo in a Parkinson's patient," Nature Neuroscience, vol. 2, no. 12, pp. 1137-1140, 1999.

[29] J. Y. Li, E. Englund, J. L. Holton et al., "Lewy bodies in grafted neurons in subjects with Parkinson's disease suggest host-tograft disease propagation," Nature Medicine, vol. 14, no. 5, pp. 501-503, 2008.

[30] J. H. Kordower, Y. Chu, R. A. Hauser, T. B. Freeman, and C. W. Olanow, "Lewy body-like pathology in long-term embryonic nigral transplants in Parkinson's disease," Nature Medicine, vol. 14, no. 5, pp. 504-506, 2008.

[31] I. Mendez, A. Vinuela, A. Astradsson et al., "Dopamine neurons implanted into people with Parkinson's disease survive without pathology for 14 years," Nature Medicine, vol. 14, no. 5, pp. 507-509, 2008.

[32] B. E. Reubinoff, P. Itsykson, T. Turetsky et al., "Neural progenitors from human embryonic stem cells," Nature Biotechnology, vol. 19, no. 12, pp. 1134-1140, 2001.

[33] S. C. Zhang, M. Wernig, I. D. Duncan, O. Brüstle, and J. A. Thomson, "In vitro differentiation of transplantable neural precursors from human embryonic stem cells," Nature Biotechnology, vol. 19, no. 12, pp. 1129-1133, 2001.

[34] H. S. Keirstead, G. Nistor, G. Bernal et al., "Human embryonic stem cell-derived oligodendrocyte progenitor cell transplants remyelinate and restore locomotion after spinal cord injury," Journal of Neuroscience, vol. 25, no. 19, pp. 4694-4705, 2005.

[35] S. M. Kang, S. C. Myung, S. Hyemyung et al., "Efficient induction of oligodendrocytes from human embryonic stem cells," Stem Cells, vol. 25, no. 2, pp. 419-424, 2007.

[36] M. S. Cho, Y. E. Lee, Y. K. Ji et al., "Highly efficient and largescale generation of functional dopamine neurons from human embryonic stem cells," Proceedings of the National Academy of Sciences of the United States of America, vol. 105, no. 9, pp. 3392-3397, 2008.

[37] D. H. Park and D. J. Eve, "Regenerative medicine: advances in new methods and technologies," Medical Science Monitor, vol. 15, no. 11, pp. RA233-RA251, 2009.

[38] T. Ben-Hur, M. Idelson, H. Khaner et al., “Transplantation of human embryonic stem cell-derived neural progenitors improves behavioral deficit in parkinsonian rats," Stem Cells, vol. 22, no. 7, pp. 1246-1255, 2004.
[39] H. Lee, G. Al Shamy, Y. Elkabetz et al., "Directed differentiation and transplantation of human embryonic stem cellderived motoneurons," Stem Cells, vol. 25, no. 8, pp. 19311939, 2007.

[40] I. H. Park, N. Arora, H. Huo et al., "Disease-specific induced pluripotent stem cells,” Cell, vol. 134, no. 5, pp. 877-886, 2008.

[41] O. Tsuji, K. Miura, Y. Okada et al., "Therapeutic potential of appropriately evaluated safe-induced pluripotent stem cells for spinal cord injury," Proceedings of the National Academy of Sciences of the United States of America, vol. 107, no. 28, pp. 12704-12709, 2010.

[42] J. Jang, H. C. Kang, H. S. Kim et al., "Induced pluripotent stem cell models from X-linked adrenoleukodystrophy patients," Annals of Neurology, vol. 70, no. 3, pp. 402-409, 2011.

[43] E. Abranches, M. Silva, L. Pradier et al., "Neural differentiation of embryonic stem cells in vitro: a road map to neurogenesis in the embryo," PLoS ONE, vol. 4, no. 7, Article ID e6286, 2009.

[44] J. Dietrich, R. Han, Y. Yang, M. Mayer-Pröschel, and M. Noble, "CNS progenitor cells and oligodendrocytes are targets of chemotherapeutic agents in vitro and in vivo," Journal of Biology, vol. 5, article 22, 2006.

[45] N. Gaspard and P. Vanderhaeghen, "Mechanisms of neural specification from embryonic stem cells," Current Opinion in Neurobiology, vol. 20, no. 1, pp. 37-43, 2010.

[46] K. Osafune, L. Caron, M. Borowiak et al., "Marked differences in differentiation propensity among human embryonic stem cell lines," Nature Biotechnology, vol. 26, no. 3, pp. 313-315, 2008.

[47] M. Denham and M. Dottori, "Signals involved in neural differentiation of human embryonic stem cells," Neuro Signals, vol. 17, no. 4, pp. 234-241, 2009.

[48] D. S. Kim, J. S. Lee, J. W. Leem et al., "Robust enhancement of neural differentiation from human ES and iPS cells regardless of their innate difference in differentiation propensity," Stem Cell Reviews and Reports, vol. 6, no. 2, pp. 270-281, 2010.

[49] S. M. Chambers, C. A. Fasano, E. P. Papapetrou, M. Tomishima, M. Sadelain, and L. Studer, "Highly efficient neural conversion of human ES and iPS cells by dual inhibition of SMAD signaling," Nature Biotechnology, vol. 27, no. 3, pp. 275-280, 2009.

[50] S. Yao, S. Chen, J. Clark et al., "Long-term self-renewal and directed differentiation of human embryonic stem cells in chemically defined conditions," Proceedings of the National Academy of Sciences of the United States of America, vol. 103, no. 18, pp. 6907-6912, 2006.

[51] T. M. LaVaute, Y. D. Yoo, M. T. Pankratz, J. P. Weick, J. R. Gerstner, and S. C. Zhang, "Regulation of neural specification from human embryonic stem cells by BMP and FGF," Stem Cells, vol. 27, no. 8, pp. 1741-1749, 2009.

[52] K. C. Davidson, P. Jamshidi, R. Daly, M. T. W. Hearn, M. F. Pera, and M. Dottori, "Wnt3a regulates survival, expansion, and maintenance of neural progenitors derived from human embryonic stem cells," Molecular and Cellular Neuroscience, vol. 36, no. 3, pp. 408-415, 2007.

[53] E. Roussa and K. Krieglstein, "Induction and specification of midbrain dopaminergic cells: focus on SHH, FGF8, and TGF$\beta$," Cell and Tissue Research, vol. 318, no. 1, pp. 23-33, 2004.

[54] Y. Yan, D. Yang, E. D. Zarnowska et al., "Directed differentiation of dopaminergic neuronal subtypes from human embryonic stem cells," Stem Cells, vol. 23, no. 6, pp. 781-790, 2005.

[55] B. Y. Hu and S. C. Zhang, "Differentiation of spinal motor neurons from pluripotent human stem cells," Nature Protocols, vol. 4, no. 9, pp. 1295-1304, 2009. 
[56] D. S. Lee, K. Yu, J. Y. Rho et al., "Cyclopamine treatment of human embryonic stem cells followed by culture in human astrocyte medium promotes differentiation into nestin- and GFAP-expressing astrocytic lineage," Life Sciences, vol. 80, no. 2, pp. 154-159, 2006.

[57] B. Li, M. Carey, and J. L. Workman, "The Role of chromatin during transcription," Cell, vol. 128, no. 4, pp. 707-719, 2007.

[58] T. I. Lee, R. G. Jenner, L. A. Boyer et al., "Control of developmental regulators by polycomb in human embryonic stem cells," Cell, vol. 125, no. 2, pp. 301-313, 2006.

[59] A. Sparmann and M. van Lohuizen, "Polycomb silencers control cell fate, development and cancer," Nature Reviews Cancer, vol. 6, no. 11, pp. 846-856, 2006.

[60] M. Spivakov and A. G. Fisher, "Epigenetic signatures of stemcell identity," Nature Reviews Genetics, vol. 8, no. 4, pp. 263271, 2007.

[61] L. A. Boyer, I. L. Tong, M. F. Cole et al., "Core transcriptional regulatory circuitry in human embryonic stem cells," Cell, vol. 122, no. 6, pp. 947-956, 2005.

[62] C. Faust, K. A. Lawson, N. J. Schork, B. Thiel, and T. Magnuson, "The Polycomb-group gene eed is required for normal morphogenetic movements during gastrulation in the mouse embryo," Development, vol. 125, no. 22, pp. 4495-4506, 1998.

[63] D. Pasini, A. P. Bracken, M. R. Jensen, E. L. Denchi, and K. Helin, "Suz12 is essential for mouse development and for EZH2 histone methyltransferase activity," EMBO Journal, vol. 23, no. 20, pp. 4061-4071, 2004.

[64] D. O'Carroll, S. Erhardt, M. Pagani, S. C. Barton, M. A. Surani, and T. Jenuwein, "The Polycomb-group gene Ezh2 is required for early mouse development," Molecular and Cellular Biology, vol. 21, no. 13, pp. 4330-4336, 2001.

[65] R. Cao and Y. Zhang, "The functions of E(Z)/EZH2-mediated methylation of lysine 27 in histone H3," Current Opinion in Genetics and Development, vol. 14, no. 2, pp. 155-164, 2004.

[66] D. Pasini, A. P. Bracken, J. B. Hansen, M. Capillo, and K. Helin, "The polycomb group protein Suz12 is required for embryonic stem cell differentiation," Molecular and Cellular Biology, vol. 27, no. 10, pp. 3769-3779, 2007.

[67] A. Golebiewska, S. P. Atkinson, M. Lako, and L. Armstrong, "Epigenetic landscaping during hESC differentiation to neural cells," Stem Cells, vol. 27, no. 6, pp. 1298-1308, 2009.

[68] S. He, T. Iwashita, J. Buchstaller, A. V. Molofsky, D. Thomas, and S. J. Morrison, "Bmi-1 over-expression in neural stem/progenitor cells increases proliferation and neurogenesis in culture but has little effect on these functions in vivo," Developmental Biology, vol. 328, no. 2, pp. 257-272, 2009.

[69] C. A. Fasano, T. N. Phoenix, E. Kokovay et al., "Bmi-1 cooperates with Foxgl to maintain neural stem cell selfrenewal in the forebrain," Genes and Development, vol. 23, no. 5, pp. 561-574, 2009.

[70] A. V. Molofsky, R. Pardal, T. Iwashita, I. K. Park, M. F. Clarke, and S. J. Morrison, "Bmi-1 dependence distinguishes neural stem cell self-renewal from progenitor proliferation," Nature, vol. 425, no. 6961, pp. 962-967, 2003.

[71] M. Román-Trufero, H. R. Méndez-Gómez, C. Pérez et al., "Maintenance of undifferentiated state and self-renewal of embryonic neural stem cells by polycomb protein Ring1B," Stem Cells, vol. 27, no. 7, pp. 1559-1570, 2009.

[72] F. Sher, R. Rößler, N. Brouwer, V. Balasubramaniyan, E. Boddeke, and S. Copray, "Differentiation of neural stem cells into oligodendrocytes: involvement of the Polycomb group protein Ezh2," Stem Cells, vol. 26, no. 11, pp. 2875-2883, 2008.
[73] X. Yao, J. R. Zhang, H. R. Huang, L. C. Dai, Q. J. Liu, and M. Zhang, "Histone deacetylase inhibitor promotes differentiation of embryonic stem cells into neural cells in adherent monoculture," Chinese Medical Journal, vol. 123, no. 6, pp. 734-738, 2010.

[74] E. Karantzali, H. Schulz, O. Hummel, N. Hubner, A. K. Hatzopoulos, and A. Kretsovali, "Histone deacetylase inhibition accelerates the early events of stem cell differentiation: transcriptomic and epigenetic analysis," Genome Biology, vol. 9, no. 4, article R65, 2008.

[75] C. J. Taylor, E. M. Bolton, S. Pocock, L. D. Sharples, R. A. Pedersen, and J. A. Bradley, "Banking on human embryonic stem cells: estimating the number of donor cell lines needed for HLA matching," Lancet, vol. 366, no. 9502, pp. 2019-2025, 2005.

[76] S. Sivarajah, G. S. Raj, A. J. V. Mathews, N. B. E. Sahib, W. S. Hwang, and J. M. Crook, "The generation of GLP-grade human embryonic stem cell banks from four clinical-grade cell lines for preclinical research," In Vitro Cellular and Developmental Biology. Animal, vol. 46, no. 3-4, pp. 210-216, 2010.

[77] A. I. Nieto, F. Cobo, A. Barroso-DelJesús et al., "Embryonic stem cell bank: a work proposal," Stem Cell Reviews, vol. 2, no. 2, pp. 117-126, 2006.

[78] J. M. Crook, D. Hei, and G. Stacey, "The international stem cell banking initiative (ISCBI): raising standards to bank on," In Vitro Cellular and Developmental Biology. Animal, vol. 46, no. 3-4, pp. 169-172, 2010.

[79] The International Stem Cell Banking Initiative, "Consensus guidance for banking and supply of human embryonic stem cell lines for research purposes," Stem Cell Reviews and Reports, vol. 5, no. 4, pp. 301-314, 2010.

[80] J. Borstlap, M. X. Luong, H. M. Rooke et al., "International stem cell registries," In Vitro Cellular and Developmental Biology. Animal, vol. 46, no. 3-4, pp. 242-246, 2010.

[81] R. M. Isasi and B. M. Knoppers, "Governing stem cell banks and registries: emerging issues," Stem Cell Research, vol. 3, no. 2-3, pp. 96-105, 2009. 

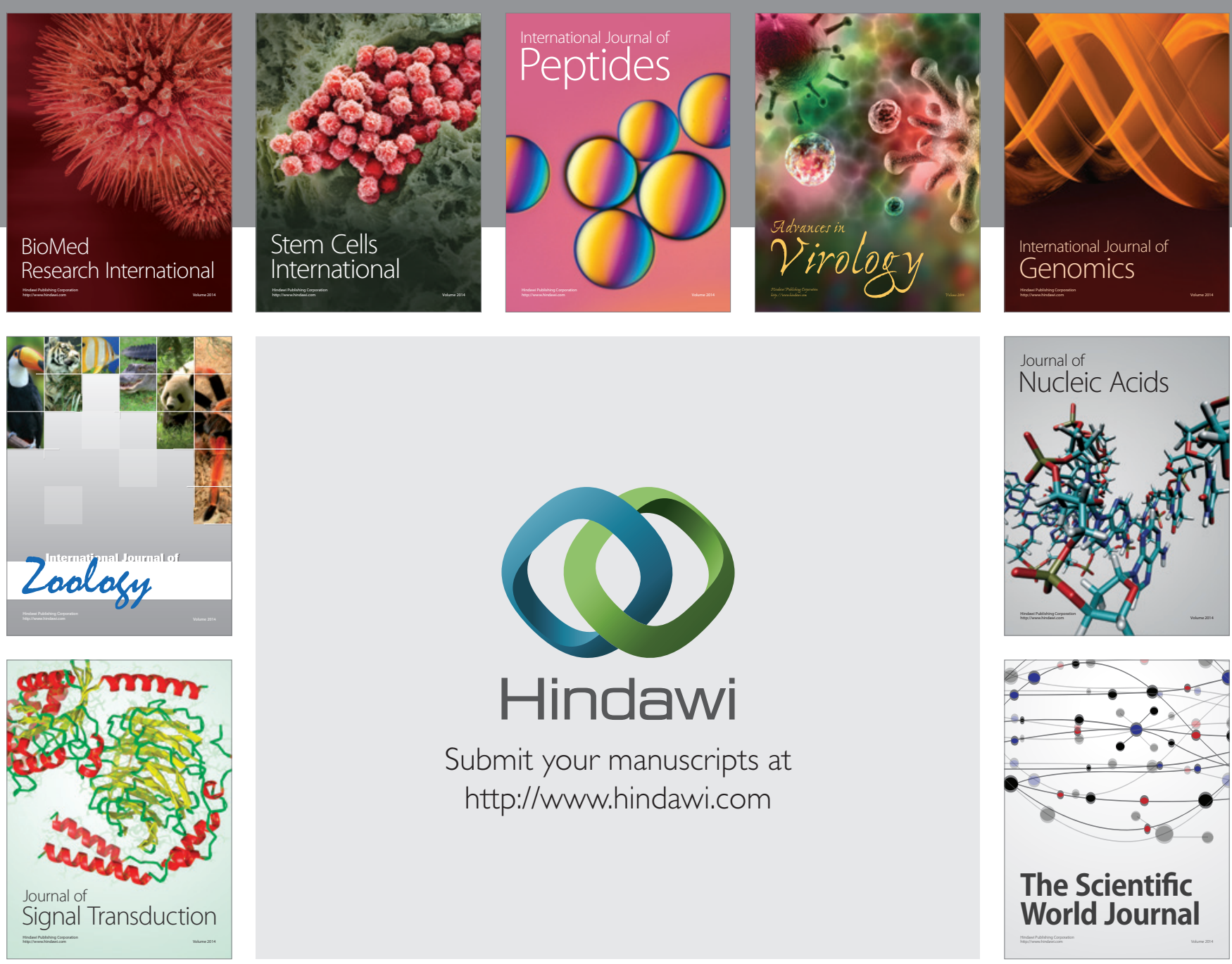

Submit your manuscripts at

http://www.hindawi.com
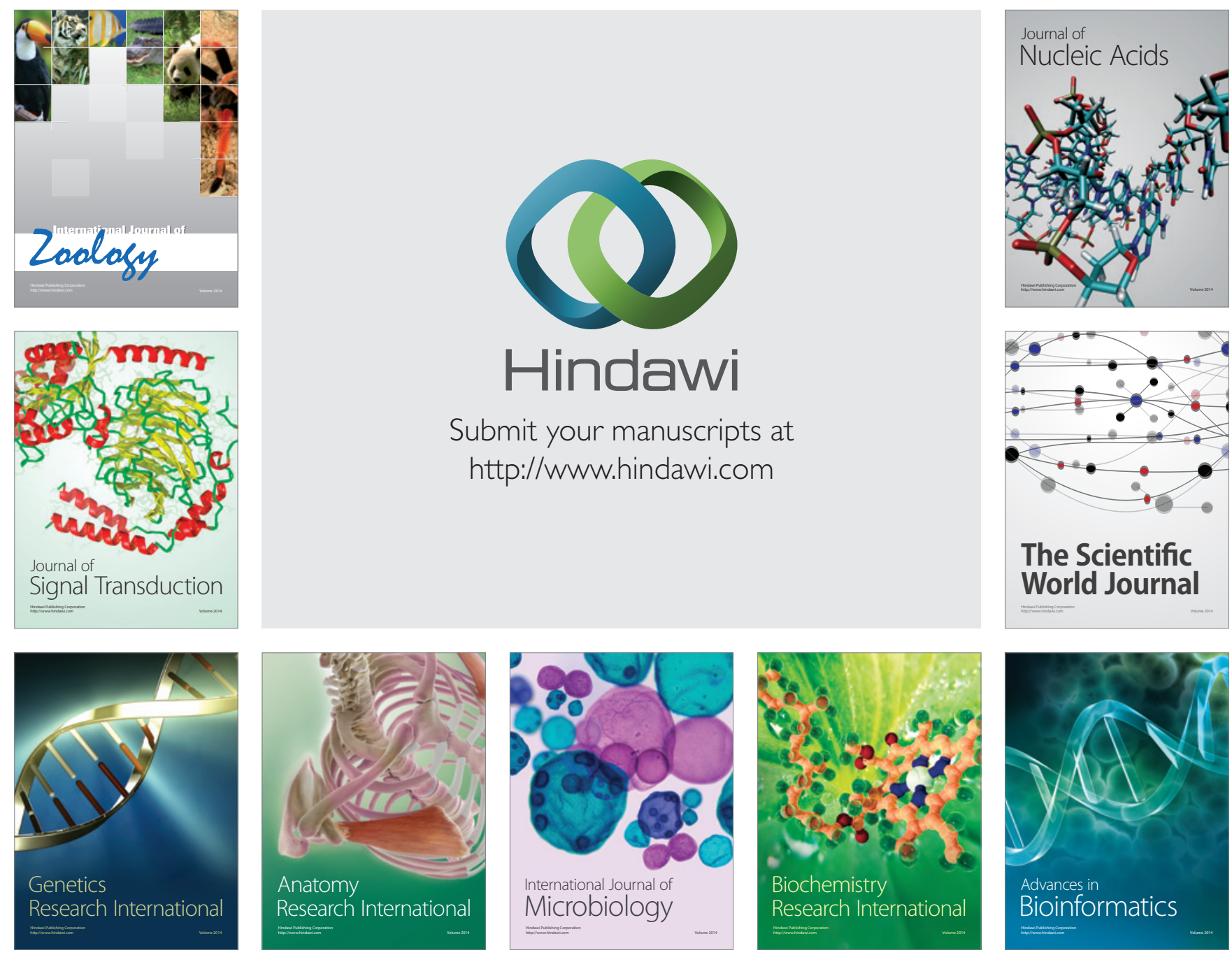

The Scientific World Journal
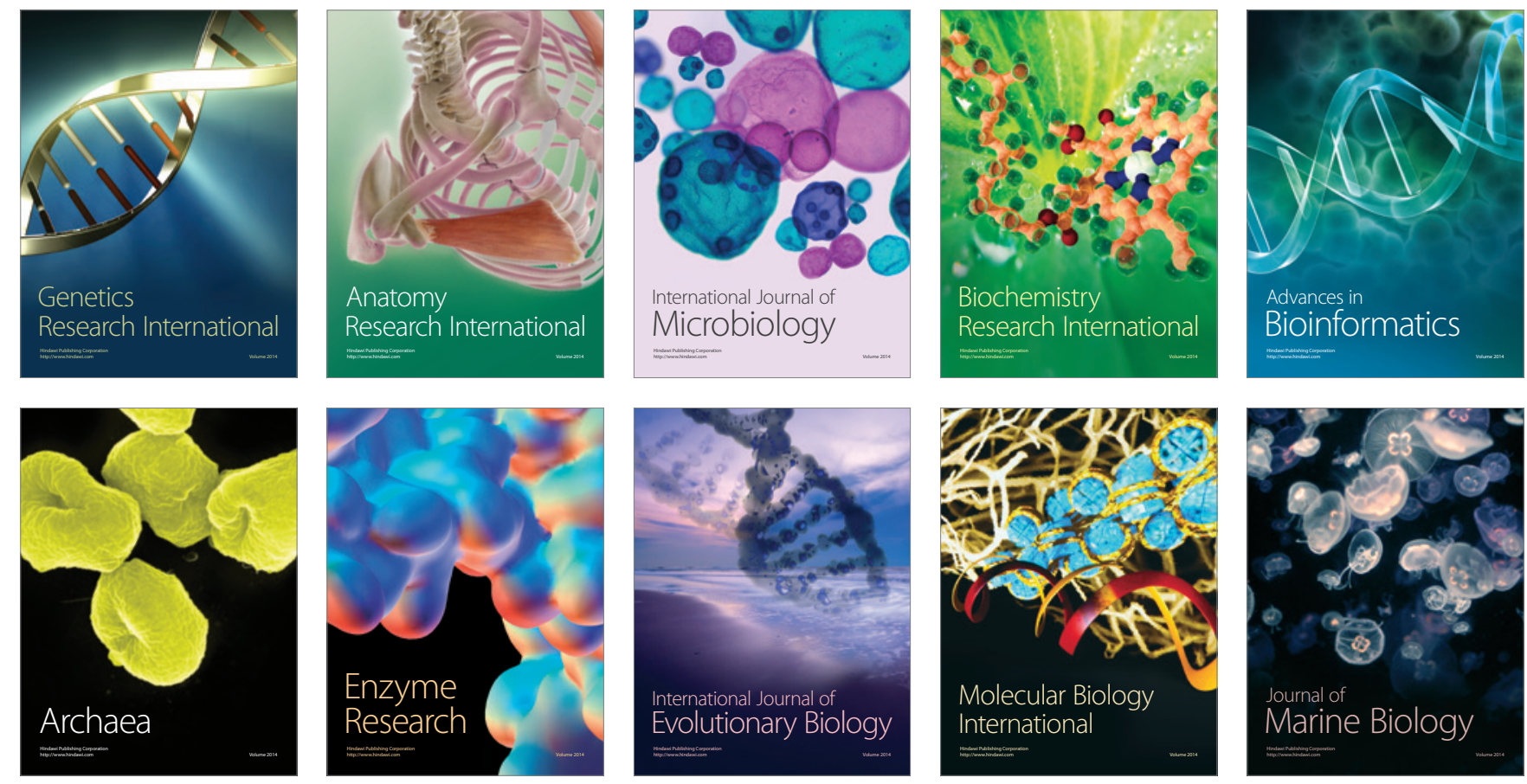